\title{
Agreement between transperineal ultrasound measurements and digital examinations of cervical dilatation during labor
}

\author{
Sigurlaug Benediktsdottir ${ }^{1 *}$, Torbjørn M. Eggeb $\varnothing^{2,3}$ and Kjell $\AA$. Salvesen ${ }^{1,3}$
}

\begin{abstract}
Background: To compare 2D transperineal ultrasound assessment of cervical dilatation with vaginal examination and to investigate intra-observer variability of the ultrasound method.

Methods: A prospective observational study was performed at Skane University Hospital, Lund, Sweden between October 2013 and June 2014. Women with one fetus in cephalic presentation at term had the cervical dilatation assessed with ultrasound and digital vaginal examinations during labor. Inter-method agreement between ultrasound and digital examinations and intra-observer repeatability of ultrasound examinations were tested.

Results: Cervical dilatation was successfully assessed with ultrasound in 61/86 (71 \%) women. The mean difference between cervical dilatation and ultrasound measurement was $0.9 \mathrm{~cm}(95 \% \mathrm{Cl} 0.47-1.34)$. Interclass correlation coefficient (ICC) was 0.83 (95\% Cl 0.72-0.90). Intra-observer repeatability was analysed in 26 women. The intra-observer ICC was 0.99 (95\% Cl 0.97-0.99). The repeatability coefficient was \pm 0.68 (95 \% Cl 0.45-0.91).

Conclusion: The mean ultrasound measurement of cervical dilatation was approximately $1 \mathrm{~cm}$ less than clinical assessment. The intra-observer repeatability of ultrasound measurements was high.
\end{abstract}

\section{Background}

Labor management is based on clinical evaluation of cervical dilatation and descent and rotation of the presenting part. Digital vaginal examination (VE) is highly subjective and operator dependent [1-4]. Some women experience VE as intimidating and uncomfortable, and repeated VEs can increase the risk of infection [5].

In recent years intrapartum sonography has been used as a complement to traditional clinical examinations. Examination of viability, fetal lie, presentation and position of the head [6-8] can be done by transabdominal ultrasound. Fetal station can be assessed with a transperineal approach by measuring fetal head-perineum distance [9-12] or angle of progression [13, 14]. Women report less pain when examined with transperineal ultrasound compared to digital examination [15].

An objective painless and simple method for assessment of cervical dilatation is warranted. Zimerman et al.

\footnotetext{
* Correspondence: sigurlaug.benediktsdottir@med.lu.se

'Department of Obstetrics and Gynecology, Clinical Sciences, Lund

University, Lund, Sweden

Full list of author information is available at the end of the article
}

has published a 3D ultrasound method [16], and Hassan et al. has suggested how to examine cervical dilatation in 2D [17]. The aims of the present study were to compare 2D ultrasound assessment of cervical dilatation with vaginal examination and to investigate intra-observer variability of the ultrasound method.

\section{Methods}

We performed a prospective observational study among 86 women in Lund, Sweden between October 2013 and June 2014. Women were recruited when a member of the study team was available, and all women gave written informed consent to participate. The Local Ethical Review Board (Lund, Sweden) approved the study (Diary number 2013/470).

Women with cephalic presentation at $\geq 37$ weeks of gestation were eligible for the study. Women in all stages of labor were examined while in a supine position with flexed knees and hips and with an empty bladder. Acquisitions were performed between contractions with a Voluson $i$ ultrasound machine (GE Medical Systems, Zipf, Austria) equipped with a 3.5-7.5 MHz 3D curved 
multifrequency transabdominal transducer. The transducer was covered with a glove and placed between labia majora in the posterior fourchette. The cervical dilatation was measured in the transverse view as described by Hassan et al. [17]. We used the mean value of the anterior-posterior and transverse diameters with the cursors placed on the inside of the cervix (inner-to-inner) as seen in Fig. 1. Two doctors and two midwives did the ultrasound examinations and 33 attending midwives did the digital examinations. The ultrasound operators were not involved in the clinical management of labor, and ultrasound operators and attending midwives were blinded to each other's assessments.

\section{Statistical analyses}

The analysis of inter-method agreement was performed using the mean of three ultrasound measurements and one digital assessment. If zero was inside the $95 \% \mathrm{CI}$ of the difference, no bias was assumed. To assess systematic bias between ultrasound measurements and digital palpation, differences between values were plotted against means of the measurements. Limits of agreement with $95 \%$ CIs of the lower and upper limits were calculated as described by Bland and Altman [18]. Inter-method agreement was also
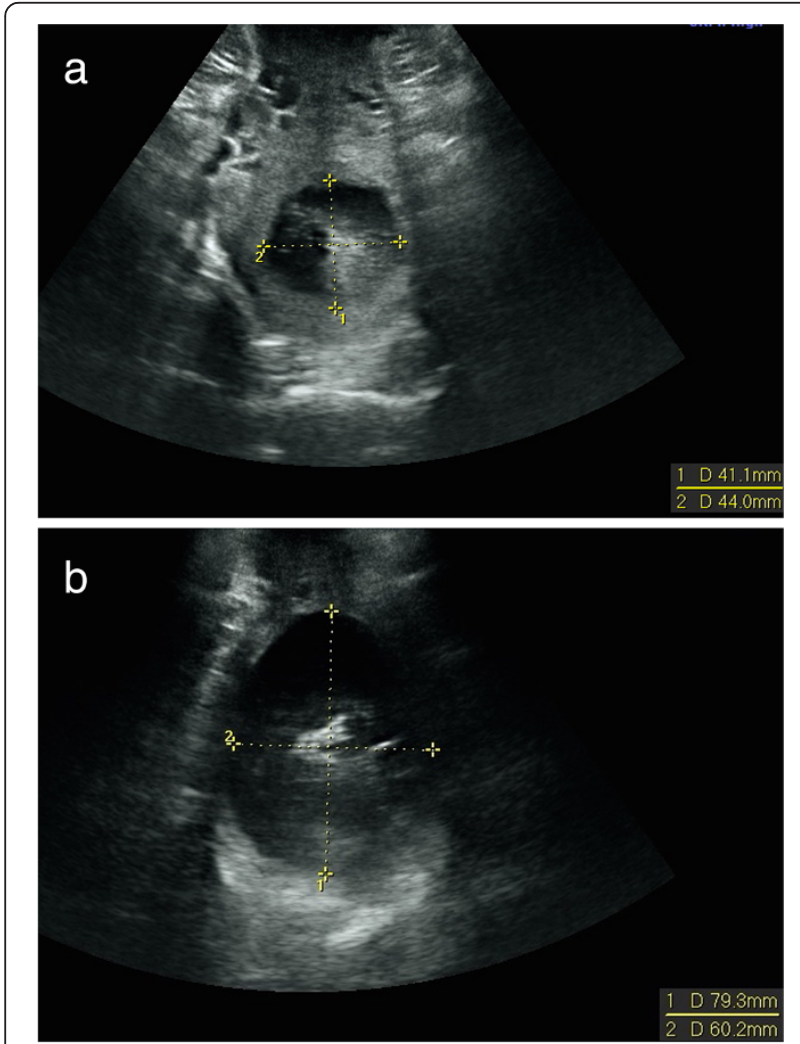

Fig. 1 Transperineal (2D) ultrasound measurement of cervical dilatation at (a) $4,3 \mathrm{~cm}$ and (b) $7,0 \mathrm{~cm}$



expressed using intraclass correlation coefficient (ICC) calculated as two-way random variation of average measurements. Linear regression analysis was performed to investigate the association between ultrasound measurements of the cervix and digital palpation. Correlations were expressed using the Pearson correlation coefficient (r).

Intra-observer repeatability of the measurements was expressed as the difference between the highest and lowest measurements and the repeatability coefficient. The differences between the first, second and third measurements were evaluated with three-way analysis of variance, and intra-observer ICC was calculated using two-way random variation of single measurements.

The data were analysed with the statistical software package SPSS statistics version 21.0 (IBM SPSS, Armonk, NY, USA).

Table 1 Characteristics of the study population

\begin{tabular}{ll}
\hline Characteristics & $\begin{array}{l}n=86 \text { median (range) } \\
\text { or } n(\%)\end{array}$ \\
\hline Mother & $30.5(23-43)$ \\
Maternal age (years) & $24.3(18-36)$ \\
Body mass index $\left(\mathrm{kg} / \mathrm{m}^{2}\right)$ & $40(36-42)$ \\
Gestational age (weeks) & $1(0-5)$ \\
Parity & \\
Labor & $23(27)$ \\
Induction of labor & $56(65)$ \\
Augmentation of labor & $38(44)$ \\
Epidural analgesia & $7(8)$ \\
Cesarean delivery & $13(15)$ \\
Operative vaginal delivery & \\
Newborn & $3665(2010-4780)$ \\
Birth weight (g)
\end{tabular}




\section{Results}

In all, 96 women were eligible for the study, and 86 women were included in the analysis. Details are presented as a flow-chart in Fig. 2.

Maternal characteristics are presented in Table 1 . Sixty-four $(74 \%)$ of 86 women were in active labor defined as cervix being dilated $\geq 4 \mathrm{~cm}$. The remaining women $(n=22)$ were in the latent phase.

Cervical dilatation was successfully assessed with ultrasound in 61/86 (71 \%) women, and there was missing data from palpation in 2 women. More than half of 25 missing cases in the ultrasound group were found when cervical dilatation was $\geq 8 \mathrm{~cm} ; 8 / 25$ (32\%) was fully dilated and 5/25 (20\%) was $8-9 \mathrm{~cm}$ dilated. When cervix was palpated $\geq 8 \mathrm{~cm}$ dilated, we were unable to measure cervical dilatation with ultrasound in $65 \%$ of women $(13 / 20)$.
Ultrasound measurements and clinical assessments were compared in 59 women. The mean cervical dilatation measured with ultrasound was $3.8 \mathrm{~cm}$, median 3.3 , (range 0.8-8.1) and the mean cervical dilatation with palpation was $4.7 \mathrm{~cm}$, median 4.0, (range $0-10$ ). The mean difference between cervical dilatation and ultrasound measurement was $0.9 \mathrm{~cm}$ (95\% CI 0.47-1.34). ICC was 0.83 (95\% CI 0.72-0.90). The agreement between the methods is presented as a Bland-Altman plot (Fig. 3). Limits of agreement were -2.34 to 4.16 . Details are presented in Table 2 .

The association between ultrasound measurements and digital examinations is presented in Fig. 4. The regression equation was $\mathrm{y}=1.7+0.8 \mathrm{x}$. Pearson correlation coefficient was 0.72 (95\% CI 0.56-0.82).

One examiner (SB) did 40 ultrasound examinations in which three measurements were successfully obtained in




Table 2 Intermethod agreement between ultrasound examinations and digital palpations

\begin{tabular}{|c|c|c|c|c|c|c|c|c|c|c|c|}
\hline \multicolumn{3}{|c|}{ Cervix dilatation $(\mathrm{cm})$} & \multirow[b]{2}{*}{ Inter-CC (95% Cl) } & \multicolumn{8}{|c|}{ Difference between the 2 methods $(\mathrm{cm})$} \\
\hline Mean & Median & Range & & Mean & $\begin{array}{l}95 \% \mathrm{Cl} \\
\text { of mean }\end{array}$ & $1.96 \mathrm{SD}$ & $\begin{array}{l}\text { Lower } \\
\text { limit }\end{array}$ & $\begin{array}{l}\text { Upper } \\
\text { limit }\end{array}$ & $\begin{array}{l}95 \% \mathrm{Cl} \text { of } \\
\text { lower limit }\end{array}$ & $\begin{array}{l}95 \% \mathrm{Cl} \\
\text { of upper limit }\end{array}$ & Range \\
\hline 4.24 & 4.65 & 0.68 to 8.45 & $0.83(0.72-0.90)$ & 0.91 & 0.47 to 1.34 & 3.25 & -2.34 & 4.16 & -3.07 to -1.61 & 3.43 to 4.89 & -3.2 to 6.17 \\
\hline
\end{tabular}

Mean, median and range for cervix dilatation are calculated from the mean of the 2 methods

Inter-CC interclass correlation coefficient, SD standard deviation

26 women. The mean dilatation was $4.63 \mathrm{~cm}$ in the first, $4.51 \mathrm{~cm}$ in the second and $4.45 \mathrm{~cm}$ in the third measurements. This was a significant trend $(p=0.03)$. The intraobserver ICC was 0.99 (95\% CI $0.97-0.99)$ and the repeatability coefficient was \pm 0.68 (95\% CI $0.45-0.91)$ ). Details are given in Table 3.

\section{Discussion}

We found transperineal ultrasound to be a suitable method to assess cervical dilatation during first stage of labor. When cervix was $\geq 8 \mathrm{~cm}$ dilated, we were unable to measure cervical dilatation in $65 \%$ of women. Ultrasound measurement of cervical dilatation was on average $1 \mathrm{~cm}$ less than digital assessment. Intra-observer repeatability of the ultrasound method was very good with ICC 0.99.
Earlier studies comparing agreement of digital assessment of cervical dilatation have shown inconsistent results. In two previous studies, in which two examiners performed VE during labor, complete agreement of cervical dilatation was found in $42-49 \%$ of cases, and $90 \%$ agreement was observed if $1 \mathrm{~cm}$ difference was allowed $[4,19]$. Another study used a spatial position-tracking ruler attached to the examiners fingertips. That study found an overall examination accuracy of $\leq 1 \mathrm{~cm}$ in $53 \%$ of women with mean error $10.2 \pm 8.4 \mathrm{~mm}$ [20]. Both Nizard et al. [20] and Buchman et al. [4] found that the accuracy of VE is best at the lower $(1-4 \mathrm{~cm})$ and upper end $(>8 \mathrm{~cm})$ of the scale for cervical dilatation. When cervix was fully dilated, the accuracy was around $75 \%$. When the cervical dilatation was $6-8 \mathrm{~cm}$, the accuracy of VE was $36-38 \%[4,20]$. In vitro studies on models

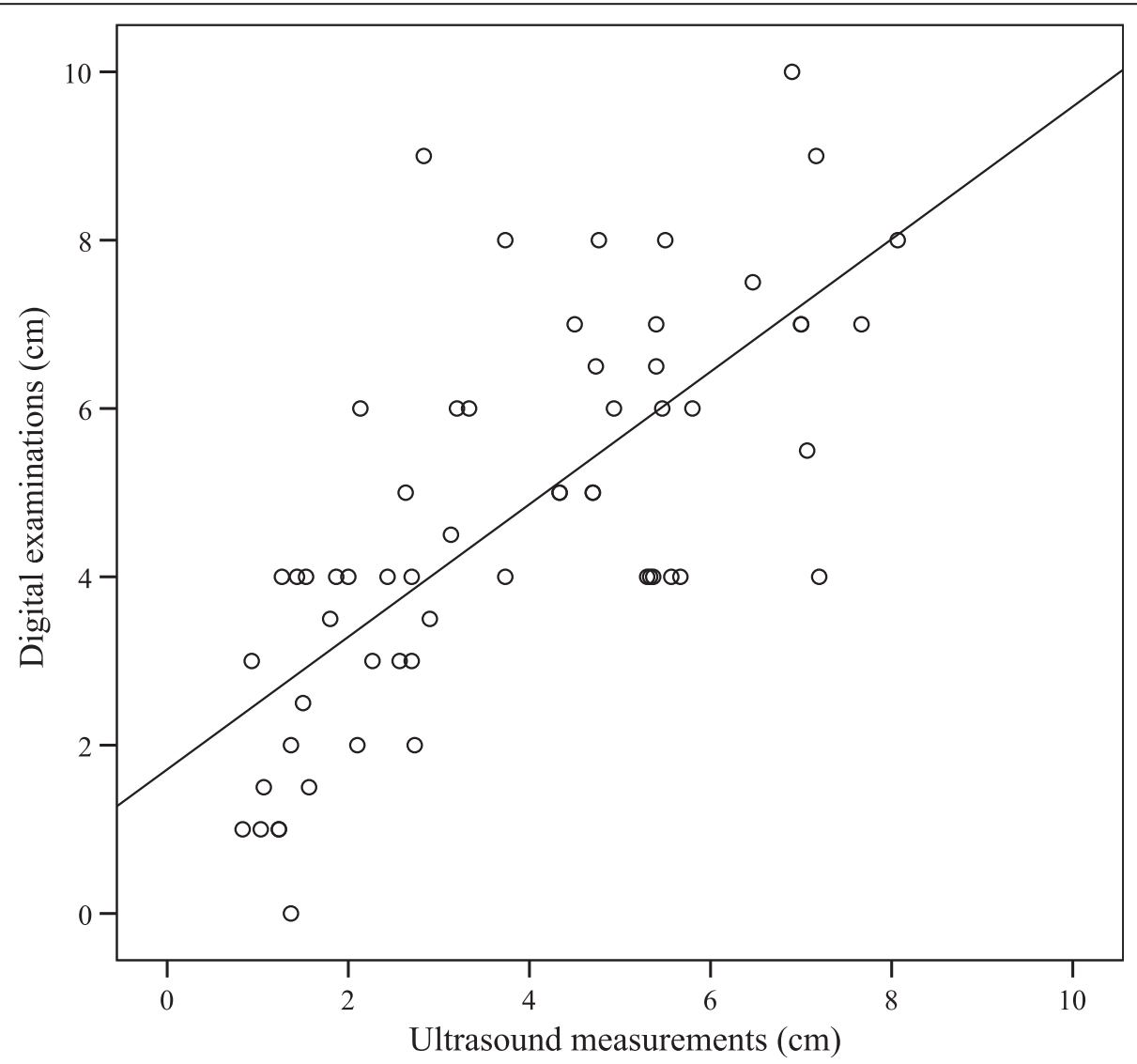

Fig. 4 Scatter plot illustrating the association between ultrasound measurements and digital examinations of cervical dilatation 
Table 3 Intraobserver repetability for ultrasound measurements of cervical dilatation

\begin{tabular}{|c|c|c|c|c|c|c|c|c|c|}
\hline \multicolumn{3}{|c|}{ Cervical dilatation $(\mathrm{cm})$} & \multirow[b]{2}{*}{ Intra-CC (95\%Cl) } & \multirow[b]{2}{*}{ Repeatability coefficient $(\mathrm{cm})(95 \% \mathrm{Cl})$} & \multicolumn{5}{|c|}{ Difference between highest and lowest values $(\mathrm{cm})$} \\
\hline Mean & Median & Range & & & $\overline{\text { Mean }}$ & Median & 10th centile & 90th centile & $\overline{\text { Range }}$ \\
\hline 4.53 & 4.60 & $1.37-7.20$ & $0.99(0.97-0.99)$ & $\pm 0.68(0.45-0.91)$ & 0.38 & 0.30 & 0.10 & 0.70 & $0-1.0$ \\
\hline
\end{tabular}

Mean, median and range of ultrasound examinations of cervical dilatation are calculated from the mean of 3 measurements

Intra-CC intraclass correlation coefficient

confirm this $[21,22]$. Phelps et al. found that the overall accuracy was $56 \%$, however, with $1 \mathrm{~cm}$ error margin the accuracy improved to $90 \%$ [22]. In vitro study with soft models have poorer accuracies (19\%) [21].

Publications on ultrasound measurement of cervical dilatation during labor are sparse. Yuce et al. found that the agreement between VE and ultrasound measurement of cervical dilatation was good with ICC 0.82 (95 \% CI 0.73-0.88), and that ultrasound measures the cervical diameter $10 \mathrm{~mm}$ smaller compared to VE [23]. Zimerman et al. [16] described how to measure cervical dilatation offline with transperineal 3D ultrasound technique and found that the mean cervical diameter had good correlation with VE. Hassan et al. [17] used 2D ultrasound measurements of the anterior-posterior diameter and found that the mean absolute difference was $1.24 \mathrm{~cm}$ between ultrasound measurement and VE. It is suggested that VE consistently overestimates the degree of cervical dilatation compared to ultrasound [24].

There are some limitations of the present study. We aimed to perform ultrasound and clinical examinations within a short time span but we did not register the time interval. We excluded two cases from the analyses because of very quick deliveries, but we cannot rule out a possibility that the observed differences were due to progression during the time interval. New studies adjusting for time intervals between examinations should be done.

Another limitation was that we did not register rupture of the membranes. In retrospective experience, it is easier to measure the cervix with ultrasound when the membranes are intact. Future studies must examine if ultrasound performs better in a group of women with intact membranes. A third limitation was that ultrasound were performed by four operators whereas digital palpations were done by 33 midwives. However, we will argue that this reflects everyday clinical practice in a busy labor ward.

Transperineal ultrasound measured the cervix 9 $\mathrm{mm}$ less dilated compared to digital palpation. This difference can be explained by the fact that cervix will distend when the examiner inserts the fingers into the cervical canal. We performed a transverse scan and measured cervical dilatation as the mean value of the anterior-posterior and the transverse diameters. Hassan et al. [17] used the anterior-posterior diameter alone in their study. It can be argued from ultrasound physics that the best measurements are obtained in the measurement plane of the anteriorposterior diameter. However, we will argue that the mean of two diameters is more appropriate when comparing with digital palpation because the examiner usually will spread the fingers in the horizontal plane. An intraobserver analysis from one operator demonstrated that the mean dilatation of cervix measured by ultrasound, decreased between the first, second and third ultrasound measurement from $4.63 \mathrm{~cm}$ in the first to $4.45 \mathrm{~cm}$ in the last examination. This difference was statistically significant, but not clinically important. The trend was not significant including analyses from all examiners $(p=0.21)$. The study population was too small to perform separate intraobserver analyses of all examiners.

We were unable to measure cervical dilatation in $65 \%$ of the women in late first stage and during second stage of labor. Measurements during these stages are more difficult because shadowing from the fetal skull makes it more difficult to identify the cervix as a distinct ring and because a thin cervix is more difficult to visualise.

Transperineal ultrasound can be used as a complement to traditional clinical examinations. Fetal station and position is more accurately assessed with ultrasound $[8,25,26]$, and the sonopartogram has been launched as a possible replacement of the traditional partogram [24]. Women report less pain when examined with transperineal ultrasound compared to digital examination [15] and replacing some of the clinical examinations with transperineal ultrasound examinations might decrease the risk of infection. Longitudinal studies evaluating the sonopartogram in normal and prolonged labor are needed.

\section{Conclusions}

In conclusion, we found that transperineal ultrasound is a suitable method to assess cervical dilatation in latent and early active stages of labor.

\section{Abbreviations}

ICC: Intraclass correlation coefficient; VE: Vaginal examination; 2D: Two dimensional; 3D: Three dimensional.

\section{Competing interests}

The authors declare that they have no competing interests. 


\section{Authors' contributions}

SB carried out all the clinical work together with the coworkers (midwives AS and $A F$ ), participated in the design of the study, the statistical analyses and drafted the manuscript. KÅS designed the study, participated in the statistical analyses and writing the manuscript. TME performed the statistical analyses and participated in writing the manuscript. All authors read and approved the final manuscript.

\section{Acknowledgements}

Anna Skärvad and Anna Forsblad participated in collection of the data. The study had no external funding.

\section{ICMJE declaration}

The authors have no involvement with commercial organisation that may have an interest in this research nor any non-financial association with any entity that may be relevant.

\section{Author details}

'Department of Obstetrics and Gynecology, Clinical Sciences, Lund University, Lund, Sweden. ${ }^{2}$ National Center for Fetal Medicine, Trondheim University Hospital (St Olavs Hospital), Trondheim, Norway. ${ }^{3}$ Department of Laboratory Medicine, Children's and Women's Health, Norwegian University of Science and Technology, Trondheim, Norway.

Received: 7 May 2015 Accepted: 13 October 2015

Published online: 24 October 2015

\section{References}

1. Phelps JY, Lambrou N, Roshanfekr D. Accuracy and intraobserver variability of simulated cervical dilatation and effacement measurements. Prim Care Update Ob Gyns. 1998:5(4):185.

2. Sherer DM, Miodovnik M, Bradley KS, Langer O. Intrapartum fetal head position I: comparison between transvaginal digital examination and transabdominal ultrasound assessment during the active stage of labor. Ultrasound Obstet Gynecol. 2002;19:258-63.

3. Tuffnell DJ, Bryce F, Johnson N, Lilford RJ. Simulation of cervical changes in labour: reproducibility of expert assessment. Lancet. 1989;2:1089-90.

4. Buchmann EJ, Libhaber E. Accuracy of cervical assessment in the active phase of labour. BJOG. 2007;114:833-7.

5. Westover T, Knuppel RA. Modern management of clinical chorioamnionitis Infect Dis Obstet Gynecol. 1995;3:123-32.

6. Youssef A, Ghi T, Pilu G. How to perform ultrasound in labor: assessment of fetal occiput position. Ultrasound Obstet Gynecol. 2013;41:476-8.

7. Dupuis O, Ruimark S, Corinne D, Simone T, Andre D, Rene-Charles R. Fetal head position during the second stage of labor: comparison of digital vaginal examination and transabdominal ultrasonographic examination. Eur J Obstet Gynecol Reprod Biol. 2005;123:193-7.

8. Akmal S, Tsoi E, Kametas N, Howard R, Nicolaides KH. Intrapartum sonography to determine fetal head position. J Matern Fetal Neonatal Med. 2002;12:172-7.

9. Tutschek B, Braun T, Chantraine F, Henrich W. A study of progress of labour using intrapartum translabial ultrasound, assessing head station, direction, and angle of descent. BJOG. 2011;118:62-9.

10. Torkildsen EA, Salvesen KA, Eggebo TM. Agreement between two- and three-dimensional transperineal ultrasound methods in assessing fetal head descent in the first stage of labor. Ultrasound Obstet Gynecol. 2012;39:310-5.

11. Eggebo TM, Heien C, Okland I, Gjessing LK, Romundstad P, Salvesen KA. Ultrasound assessment of fetal head-perineum distance before induction of labor. Ultrasound Obstet Gynecol. 2008;32:199-204.

12. Rivaux G, Dedet B, Delarue E, Depret S, Closset E, Deruelle P. The diagnosis of fetal head engagement: transperineal ultrasound, a new useful tool? Gynecol Obstet Fertil. 2012;40:148-52.

13. Kalache KD, Duckelmann AM, Michaelis SA, Lange J, Cichon G, Dudenhausen JW. Transperineal ultrasound imaging in prolonged second stage of labor with occipitoanterior presenting fetuses: how well does the 'angle of progression' predict the mode of delivery? Ultrasound Obstet Gynecol. 2009;33:326-30.

14. Barbera AF, Pombar X, Perugino G, Lezotte DC, Hobbins JC. A new method to assess fetal head descent in labor with transperineal ultrasound. Ultrasound Obstet Gynecol. 2009;33:313-9.
15. Chan Y, Lau W, Lo T, Leung W. OC07.05: comparison of pain score between translabial ultrasound and digital vaginal examination during active labour. Ultrasound Obstet Gynecol. 2014;44:17.

16. Zimerman AL, Smolin A, Maymon R, Weinraub Z, Herman A, Tobvin Y. Intrapartum measurement of cervical dilatation using translabial 3-dimensional ultrasonography: correlation with digital examination and interobserver and intraobserver agreement assessment. J Ultrasound Med. 2009;28:1289-96.

17. Hassan WA, Eggebo TM, Ferguson M, Lees C. Simple two-dimensional ultrasound technique to assess intrapartum cervical dilatation: a pilot study. Ultrasound Obstet Gynecol. 2013;41:413-8.

18. Bland JM, Altman DG. Statistical methods for assessing agreement between two methods of clinical measurement. Lancet. 1986;1:307-10.

19. Bergsjo P, Koss KS. Interindividual variation in vaginal examination findings during labor. Acta Obstet Gynecol Scand. 1982;61:509-10.

20. Nizard J, Haberman S, Paltieli Y, Gonen R, Ohel G, Nicholson D, et al. How reliable is the determination of cervical dilation? Comparison of vaginal examination with spatial position-tracking ruler. Am J Obstet Gynecol. 2009;200:402.e1-4.

21. Huhn KA, Brost BC. Accuracy of simulated cervical dilation and effacement measurements among practitioners. Am J Obstet Gynecol. 2004;191:1797-9.

22. Phelps JY, Higby K, Smyth MH, Ward JA, Arredondo F, Mayer AR. Accuracy and intraobserver variability of simulated cervical dilatation measurements. Am J Obstet Gynecol. 1995;173:942-5

23. Yuce T, Kalafat E, Koc A. Transperineal ultrasonography for labor management: accuracy and reliability. Acta Obstet Gynecol Scand. 2015:94:760-5.

24. Hassan WA, Eggebo T, Ferguson M, Gillett A, Studd J, Pasupathy D, et al. The sonopartogram: a novel method for recording progress of labor by ultrasound. Ultrasound Obstet Gynecol. 2014;43:189-94.

25. Eggebo TM, Hassan WA, Salvesen KA, Torkildsen EA, Ostborg TB, Lees CC. Prediction of delivery mode with ultrasound assessed fetal position in nulliparous women with prolonged first stage of labor. Ultrasound Obstet Gynecol. 2014. doi:10.1002/uog.14773.

26. Eggebo TM, Hassan WA, Salvesen KA, Lindtjorn E, Lees CC. Sonographic prediction of vaginal delivery in prolonged labor: a two-center study. Ultrasound Obstet Gynecol. 2014;43:195-201.

\section{Submit your next manuscript to BioMed Central and take full advantage of:}

- Convenient online submission

- Thorough peer review

- No space constraints or color figure charges

- Immediate publication on acceptance

- Inclusion in PubMed, CAS, Scopus and Google Scholar

- Research which is freely available for redistribution 